\title{
Governo - um aliado nem sempre lembrado pelas empresas na hora de desenvolver as atividades de P\&D*
}

\author{
Manoela Silveira dos Santos** \\ Ivan Antônio Pinheiro***
}

Sumário: 1. Introdução; 2. Do triângulo de Sábato à triple helix; 3. O alinhamento necessário entre as políticas industrial e tecnológica; 4. Bases de uma política sustentável de inovação: da P\&D para a C\&T; 5. Considerações finais.

Summary: 1. Introduction; 2. From Sábato to triple helix; 3. The necessary alignment between industrial and technological policies; 4. Bases of a sustainable innovation policy: from R\&D to S\&T; 5. Final considerations.

Palavras-chave: governo; pesquisa e desenvolvimento (P\&D); tecnologia; inovação; desenvolvimento.

KEY worDs: government; research \& development (R\&D); technology; innovation; development.

Pelo menos três agentes - o governo, a indústria e as instituições de ensino e pesquisa — devem atuar solidariamente na criação e no desenvolvimento do conhecimento. Mesmo com características distintas, devem atuar de forma cooperada para que os ganhos se multipliquem e estendam pela cadeia produtiva. Na sociedade do conhecimento, investir em P\&D é quase que uma imposição para que haja desenvolvimento econômico e social. O governo brasileiro tem sido, por muito tempo, o responsável pela maior parte dos investimentos em P\&D, no entanto hoje existem diversas iniciativas para estimular o investimento privado em P\&D. Os objetivos deste trabalho são discutir as principais iniciativas do governo brasileiro, nos últimos 10 anos, que influenciarão no desenho das atividades de P\&D no país, a fim de obter uma

* Artigo recebido em out. 2009 e aceito em out. 2010.

** Doutoranda do Programa de Pós-graduação em Administração (PPGA) da Universidade Federal do Rio Grande do Sul (UFRGS). Endereço: rua Wilson Adnislen de Paiva Bueno, 41, ap. 515 — Cavalhada - CEP 90830-244, Porto Alegre, RS, Brasil. E-mail: manoela81@yahoo.com.br; manoelasantos@bol.com.br.

*** Professor da Escola de Administração da UFRGS. Endereço: rua Washington Luiz, 855 — Centro — CEP 90010-460, Porto Alegre, RS, Brasil. E-mail: iapinheiro@ea.ufrgs.br. 
melhor compreensão acerca do papel do governo na promoção do P\&D. A análise conjunta dos marcos institucionais possibilita perceber a força transformadora que provocarão no cenário, o que não seria possível se vistos isoladamente. Este artigo buscou convergir estas iniciativas para obter uma melhor compreensão acerca do papel do governo na promoção do P\&D. Pode-se observar que o governo brasileiro é um importante parceiro para as empresas interessadas em investir em P\&D; no entanto, muitas delas não o veem nesta posição.

Government - a partner not always remembered by companies, when developing R\&D activities

At least three agents - government, industry, and teaching and research institutions -, should act based on solidarity to promote knowledge creation and development. Even being different, they should work in cooperation, so that profits can be multiplied and extended throughout the whole productive chain. In the knowledge society, investing in Research \& Development (R\&D) is more than necessary; it is an imperative to the economic and social development. Brazilian Government has been the responsible for most investments in R\&D for many years, nevertheless, today there are several governmental initiatives to encourage private investment in $R \& D$ activities. According to that status, this study aims at presenting and discussing the main initiatives promoted by the Brazilian government over the past 10 years that represent the style to manage technology and growth in the country. A jointly analysis of those institutional landmarks can explain the transforming strength in this scenario, which would be not possible by doing a individually analyze. This paper tried to congregate initiatives to obtain a better comprehension regarding the Government role in R\&D promotion. Brazilian Government is an important partner to companies interested in R\&D, however, most companies does not see him in this position.

\section{Introdução}

As atividades de criação, desenvolvimento e difusão do conhecimento, apesar de distintas, devem andar próximas, eis que o êxito de uma pode catalisar e impulsionar o sucesso da etapa subsequente, favorecendo o surgimento de um círculo efetivamente virtuoso. Ademais, pelo menos três agentes devem atuar solidariamente: o governo, a indústria (genericamente equivalente ao setor produtivo) e as instituições de ensino e pesquisa. Distintos quanto à missão e à formatação institucional (processo decisório, fontes de financiamento etc.), devem, contudo, e até mesmo pelas suas diferenças, atuar de forma cooperada, promovendo, assim, sinergias, resultados e ganhos que beneficiam toda a cadeia produtiva. Seu reconhecimento é antigo, no entanto, foi somente a partir do início do século passado, mais precisamente após a crise de 1929, que 
as ações compartilhadas começaram a merecer por parte da gestão, pública e privada, maior atenção e esforços.

Após as pioneiras reflexões de Schumpeter, atendo-se ao passado mais recente, Sábato e Etzkowitz destacam-se entre os que aportaram relevantes contribuições à necessária ação articulada e cooperada entre os agentes econômicos. Grosso modo, através da figura do triângulo, Sábato sugere que cada um dos vértices, o governo, a indústria e meio acadêmico, desenvolva atividades especializadas; enquanto que a triple helix, de Etzkowitz (2003), reconhece a primazia de determinados atores para certos papéis, contudo, admite como natural que um dos vértices exerça, circunstancialmente, também, o papel do outro.

Na sociedade do conhecimento, investir em P\&D é quase que uma imposição, vista como uma condição sine qua non ao domínio das tecnologias necessárias ao desenvolvimento econômico e social. Em virtude desse reconhecimento, no Brasil, o governo, através das instituições federais de ensino superior (Ifes), já há muitos anos tem sido o responsável pela maior parte dos investimentos em P\&D. Todavia, contínuos e crescentes desequilíbrios fiscais fizeram com que o modelo fosse repensado; assim, hoje se observam várias iniciativas governamentais para estimular o maior envolvimento do setor privado com as atividades de P\&D.

Tanto os países quanto as empresas direcionam sua atenção para a inovação, para tal são necessários investimentos. As empresas, para inovar, recorrem a variadas fontes: aos projetos de clientes, à cadeia de suprimentos, à obtenção de licenças, à engenharia reversa ou mesmo à simples cópia. A cada fonte, além das vantagens e desvantagens intrínsecas, a exemplo dos diferentes níveis de custos, prazos, riscos, ganhos etc., podem ainda ser associados diferentes graus de sustentabilidade no que tange ao diferencial competitivo que proporcionam. A opção por gerar conhecimento e inovar a partir da P\&D (própria ou compartilhada) se, de um lado, é tida como uma das mais arriscadas, de outro, pode proporcionar vantagens exclusivas e, por isso, sustentáveis no longo prazo. Incertezas quanto às bases teóricas, à funcionalidade, à operacionalidade, à aceitação pelo mercado, entre outras, ampliam as expectativas de riscos e tendem a afastar as empresas da aventura dos empreendimentos, próprios ou compartilhados, no domínio da $\mathrm{P} \& \mathrm{D}$, daí a relevância da atuação governamental efetiva nessa área para alavancar o desenvolvimento econômico e social.

Dado esse quadro, os objetivos deste trabalho são apresentar e discutir as principais iniciativas, de incentivo às atividades de $\mathrm{P} \& \mathrm{D}$, promovidas pelo governo brasileiro. Vistas isoladamente, por terem sido editadas em diferentes 
governos e períodos, parece não ter sido ainda compreendida a força transformadora subjacente aos mais recentes marcos institucionais. Os levantamentos, depoimentos e entrevistas junto aos agentes do setor privado e veiculados na mídia sugerem que os mesmos ainda não perceberam que eles têm, no governo, um parceiro nos empreendimentos para gerar e desenvolver as novas bases de conhecimentos necessários às inovações, sobretudo, as denominadas radicais. Acredita-se e se procurará demonstrar ao longo deste texto que essas iniciativas, no médio e longo prazos, devem redesenhar o mapa das atividades de P\&D no país, bem como a participação relativa do setor público e privado.

Trata-se de um ensaio analítico e crítico; contudo, avança e tece considerações prospectivas. Ampara a contribuição dos autores, uma ampla consulta aos principais textos normativos que nos últimos 10 anos foram editados pelo governo brasileiro: 1) o Sistema de Proteção Intelectual; 2) os Fundos Setoriais - fontes básicas de financiamento das atividades de P\&D; 3) a criação do Centro de Gestão de Estudos Estratégicos (CGEE); 4) a criação de Incentivos Fiscais para a Atualização Tecnológica Setorial; e, 5) a instituição de estímulos à formatação de parceria entre entidades públicas e organizações privadas, tendo por objetivo específico a promoção da pesquisa tecnológica e a geração de inovações patenteáveis.

\section{Do triângulo de Sábato à triple helix}

Nos anos 1960, atento e preocupado com as políticas públicas e com os arranjos institucionais que poderiam alavancar o desenvolvimento socioeconômico da América Latina, J. Sábato (1974) elaborou uma proposição, por vezes também referida como Modelo, em que no vértice superior de um triângulo equilátero se encontraria o governo e, na base, de um lado o setor produtivo, também referido como industrial, e, do outro, as instituições responsáveis pela pesquisa e o ensino. O que chama a atenção no modelo de Sábato é, em primeiro lugar, o caráter de especialização, quase que de exclusividade dos papéis exercidos pelos agentes situados nos respectivos vértices e, em segundo, como decorrente da proposição inicial, a necessária segmentação e linearidade do processo de geração e difusão do conhecimento.

Nessa linha, caberia aos governos criar as condições institucionais, normativas e de fomento que servissem de estímulo e garantia à atuação dos demais agentes, a exemplo: 1) de definir marcos regulatórios estáveis; 2) de assegurar o seu adequado funcionamento, ou seja, as condições de enforcement; 3 ) de estabelecer padrões (normalização técnica); 4) de tornar públicas as suas 
diretrizes, explicitando-as nos programas, planos e orçamentos públicos; 5) de eleger e fomentar determinados setores, seja motivado por visão estratégica ou pelos efeitos multiplicadores (progresso técnico, geração de empregos etc.) que exerceriam sobre as demais cadeias produtivas e economias regionais; 6) entre outras iniciativas. O papel, bem como a importância dos governos como indutores do progresso baseado no conhecimento científico têm sido reconhecidos por vários autores (Pavitt e Walker, 1976; Allen et at., 1978; Marcovitch et al., 1991; Freeman, 1998), sendo amplo o rol de iniciativas à disposição das autoridades governamentais.

Já as instituições de ensino e pesquisa seriam as responsáveis pelas atividades traduzidas na própria denominação do setor - o ensino e a pesquisa —, constituindo a infraestrutura técnico-científica necessária à economia e ao parque produtivo nacional. Os resultados da pesquisa básica deveriam, então, ser transferidos para o terceiro vértice - o setor produtivo - , que se encarregaria de converter o conhecimento adquirido na forma de produtos e serviços disponibilizados no mercado.

No entanto, apesar de o Modelo de Sábato sugerir a especialização dos vértices, as evidências empíricas nem sempre o confirmam. Sabe-se que os governos possuem duplo papel: ora atuam como autoridades governamentais propriamente ditas, regulando e fomentando, ora, mediante suas empresas, seguem a lógica do mercado, competindo e buscando a maximização dos resultados. Do mesmo modo, as instituições de ensino e pesquisa nem sempre realizam pesquisa tendo em vista somente a ampliação do estado da arte do conhecimento; esta às vezes também é orientada a partir de necessidades do setor produtivo e que demanda soluções tecnológicas, portanto, de cunho prático. Por fim, afirmar que o setor produtivo não teria interesse (devido à incerteza quanto aos prazos, ao volume de recursos necessários e aos riscos) no desenvolvimento de pesquisa básica, optando por concentrar esforços no posterior desenvolvimento e na exploração comercial, é ignorar as evidências empíricas da história (em especial após a II Revolução Industrial) e, entre outras, as recomendações de Schumpeter (1988), que já no início do século XX identificara a importância das atividades de P\&D como fonte de inovação, vantagem competitiva e sustentabilidade das empresas.

Mesmo sob críticas, o Modelo de Sábato tem sido uma referência, não só porque é simples (obedece ao princípio de Occam), mas, sobretudo, porque há casos em que se revela como uma útil e poderosa ferramenta para explicar o comportamento dos agentes que identifica e orientar a formulação de políticas públicas (PP). Todavia, não pode se perder de vista que ele foi concebido (sob inspiração da Cepal) em um momento histórico de acentuada polarização 
política como uma baliza para orientar a formulação e a implementação de PP em países subdesenvolvidos ou em desenvolvimento incipiente, caracterizados por grandes desigualdades sociais e baixo nível de poupança privada, daí a centralidade da atuação do vértice governo na construção da infraestrutura técnico-científica vista como condição sine qua non ao desempenho do aparelho produtivo.

No Brasil, há várias iniciativas que ilustram o êxito da triangulação de Sábato a partir de um conjunto de iniciativas governamentais. Provavelmente uma das mais (re)conhecidas é o domínio, por parte da indústria nacional, da tecnologia de exploração de petróleo em águas profundas - uma política pública capitaneada por uma empresa estatal, a Petrobras. A indústria naval, a aeronáutica, e mesmo a bélica leve também experimentaram um relativo sucesso que, todavia, não logrou continuidade. Mais recente e igualmente notório é o domínio do ciclo da tecnologia do álcool combustível, cujos estímulos governamentais, para o setor acadêmico e para a indústria, foram significativos, constituindo o Programa Nacional do Álcool (Proalcool).

Ao longo da história a divisão de competências entre os vértices experimentou momentos de grande aproximação e, aos poucos, as lógicas e os paradigmas dominantes foram, mutuamente, se aceitando e se mesclando na origem de uma nova cultura de geração e difusão do conhecimento. As sucessivas mudanças no ambiente contribuíram para essa aproximação, assim como para que fossem identificados novos arranjos institucionais capazes de superar as dificuldades emergentes. Surge, então, o Modelo da triple helix, que além de reconhecer a necessária e indispensável interação entre os vértices, admite que um, além da sua atividade precípua, acumule a de outro - uma indústria pioneira e hegemônica pode, por exemplo, definir padrões, ao invés de o governo fazê-lo. Observa-se que se trata de uma concepção mais ampla e flexível no que tange ao papel dos agentes.

\section{O Alinhamento necessário entre as políticas industrial e tecnológica}

É reconhecido que o conhecimento científico e o progresso técnico são as principais alavancas para o desenvolvimento econômico. Contudo, os governos, sobretudo o dos países em desenvolvimento, são pressionados por demandas igualmente importantes e cujos resultados devem ser apresentados no curto, quando não no curtíssimo prazo, a exemplo das demandas provenientes das áreas da saúde, do saneamento e da segurança, entre outras. De outro lado, 
o setor privado, pelos motivos já citados, não se sente motivado para alocar recursos em $\mathrm{P} \& \mathrm{D}$, principalmente em áreas cujos resultados podem ser apropriados por outros agentes da sociedade. Cabe, então, à ação governamental, sobremodo na forma de agente regulador e fomentador, constituir a base de uma política industrial e tecnológica.

Nos países de desenvolvimento tardio, uma das primeiras iniciativas é o estímulo à incorporação de tecnologias na forma de importação de bens de capital ou através da aquisição de licenças. Embora abrevie o domínio de certos campos de conhecimento, tais práticas têm sérios inconvenientes, não promovem mudanças nas condições institucionais de educação e capacitação de recursos humanos para a $\mathrm{P} \& \mathrm{D}$, indispensáveis ao efetivo catch-up descrito por Gershenkron (1962). Ademais, nem sempre as tecnologias disponíveis no mercado são as demandadas pelo país, que possui condições naturais, recursos, necessidades e prioridades específicas. Assim, além de ser mantido o subdesenvolvimento, não se criam as condições essenciais à aquisição e incorporação, pelo setor produtivo, de tecnologias mais avançadas (Marcovitch et al., 1991; Freeman, 1998). Contudo, devido à incerteza, tanto o setor público quanto as empresas preferem assimilar o conhecimento existente a correr riscos na geração de novos conhecimentos, sendo postergados, assim, os investimentos em P\&D endógenos.

Durante muitos anos o Brasil teve por política incorporar tecnologias prontas; entretanto, a partir dos anos 1960 houve uma inflexão, quando foram criadas instituições de apoio ao desenvolvimento da Ciência e Tecnologia (C\&T) através de atividades de P\&D nas universidades, institutos de pesquisa e mesmo nas empresas. Políticas gerais, regionais e setoriais foram implementadas, observando-se, ainda, o necessário alinhamento com a política econômica, e a industrial; os resultados não tardaram (Marcovitch et al., 1991) com repercussões também na esfera social. Embora sempre referida e demandada, a importância da ação das autoridades governamentais não se esgota na transferência e na provisão de recursos do setor público para o desenvolvimento de uma política de C\&T apoiada na P\&D; destaca-se, também, o papel do governo como agente sinalizador dos rumos, constituindo e balizando, através de regulamentação, o ambiente econômico-industrial (Pavitt e Walker, 1976; Allen et al., 1978).

Desde então, o governo passa a incentivar o desenvolvimento científico e tecnológico do país, através, entre outras práticas, da busca pela maior integração entre universidades, empresas e o capital financeiro, bem como contribuindo para constituir a infraestrutura de capacitação de recursos humanos (financiamentos através de bolsas de estudo, estímulo aos in- 
tercâmbios com instituições do exterior, laboratórios etc.) (Marcovitch et al., 1991). No Brasil, apesar de crescentes, os investimentos em $P \& D$ ainda são modestos, mesmo se comparados com países em desenvolvimento: no país, em 2000, os investimentos em P\&D representaram 1,05\% do PIB, contra $2,76 \%$ dos EUA e os 2,47\% registrados pela Coreia do Norte. No período, os investimentos do governo foram na ordem de $\mathrm{R} \$ 11.455,20$ milhões, representando $60,2 \%$ do total, cabendo ao setor privado outros $\mathrm{R} \$ 4.560,70$ milhões (39,8\%) (MCT, 2009).

Por um lado, existem os que afirmam que a oferta cria sua própria demanda, princípio conhecido como a Lei de Say (1767-1832) — por exemplo, o prof. H. Petroski, da Universidade de Duke, afirma que "A invenção é a mãe da necessidade. Ninguém precisava do iPod ou do telefone celular antes que eles fossem inventados" - , de outro, há os que observaram que a necessidade é que tem motivado o surgimento das inovações. Contudo, independentemente do princípio prevalecente, são necessários recursos, bem como clareza acerca da natureza do conhecimento técnico-científico indispensável às iniciativas inovadoras, sobretudo se emergentes no setor industrial. Muitos desses recursos são externos, direta ou indiretamente, e em diferentes graus, o governo se torna responsável por parte deles (Pavitt e Walker, 1976). Nesse ambiente, são necessários alguns fatores-base para a emergência da inovação, bem como sua difusão na indústria, sendo merecedores de destaque: (i) a educação para inovação - referente não só à mão de obra necessária, mas à formação de uma massa crítica que crie e construa o conhecimento, básico e aplicado; (ii) a infraestrutura - centros de pesquisas, laboratórios e universidades; (iii) o financiamento - linhas e taxas especiais para incentivar a $\mathrm{P} \& \mathrm{D}$, principalmente em áreas consideradas essenciais pelo governo; (iv) as políticas públicas — para estimular a inovação através da $\mathrm{P} \& \mathrm{D}$; e, (v) as ações para impulsionar as relações entre os atores, notadamente entre as universidades e a indústria (Pavitt e Walker, 1976; Freeman, 1998; Marcovitch et al., 1991).

A ação governamental se dá tanto de forma direta quanto indireta, sendo esta uma tendência em razão das vantagens que os incentivos (fiscais, mercadológicos, administrativos e legais) apresentam: a flexibilidade de reorganização do projeto, se necessária; a rapidez de implementação; o baixo custo; o volume dos incentivos (em P\&D), que tende a ser mantido mesmo em épocas de instabilidade econômica; a maior interação entre as empresas, as universidades e os centros de pesquisas; a menor burocracia e, por conseguinte, a maior autonomia das empresas. O contraponto são as desvantagens observadas pelo empresariado: maior exposição e risco em face das mudanças 
políticas; a tendência de as maiores e mais organizadas empresas acumularem mais benefícios (Marcovitch et al., 1991).

Os governos também apontam as desvantagens, em particular, a maior dificuldade de controle, mormente em razão da amplitude do conceito (atividades) abarcado sob a denominação genérica de $\mathrm{P} \& \mathrm{D}$, o que possibilita que os incentivos sejam utilizados em áreas inicialmente não planejadas - fora da agenda das prioridades governamentais - , e casos de desvios com o intuito de, tão somente, ter acesso a uma fonte extraordinária de recursos (Marcovitch et al., 1991). Por fim, o marco regulatório setorial, isto é, das atividades de $C \& T$ e $P \& D$, pode se constituir, ou não, conforme a habilidade governamental, em um quadro de incentivos.

Após essa breve retrospectiva sobre a relevância da ação governamental no campo objeto desse estudo, tendo-se já orientado o foco para a experiência brasileira, na sequência serão apresentadas as mais recentes e importantes iniciativas do governo brasileiro com vistas a construir o macro ambiente institucional que seja estimulante às atividades de $\mathrm{P} \& \mathrm{D}$, suporte à C\&T necessária à inovação.

\section{Bases de uma política sustentável de inovação: da P\&D para a C\&T}

\section{As Leis de propriedade intelectual}

Mesmo como um dos principais instrumentos utilizados pelos governos para o estímulo à pesquisa, sobretudo a conduzida pelo setor privado, o sistema de proteção intelectual, no Brasil, é bastante recente, datando de 1996. Esta circunstância é apontada como responsável pelo quadro de desnível observado, entre o setor público $\times$ privado, nas atividades de $\mathrm{P} \& \mathrm{D}$ realizadas no país, uma vez que, sem a garantia da proteção estatal ao exercício do direito de exploração exclusiva do conhecimento gerado, para muitas empresas não seria vantajoso investir em $P \& D$.

O poder de monopólio para explorar os resultados de uma inovação é tido como um dos fatores determinantes na tomada de decisão das organizações que se lançam (ou não) em tais empreendimentos (Pavitt e Walker, 1976). Nessa direção, o governo brasileiro instituiu quatro leis, uma geral e três específicas: 1) a dos direitos e obrigações relativos à propriedade industrial; 2) a de proteção aos cultivares; 3) a chamada "Lei do Software", que dispõe sobre a proteção da propriedade intelectual de programa de compu- 
tador, bem como sua comercialização no país; e 4) atualizou e consolidou a legislação sobre direitos autorais.

De um modo geral, a Lei de Propriedade Intelectual — Lei no 9.279/1996 —, que regula os direitos relativos à propriedade intelectual no Brasil, não difere, sobremodo, de outras similares. Assim, e desde então, os empreendedores públicos ou privados passam a contar com a proteção do Estado para explorar, em regime de monopólio, os ganhos obtidos a partir dos resultados das pesquisas desenvolvidas. Destarte, se bem-sucedida uma inovação, antes que caia em domínio público, os investimentos poderão ser amortizados e acumulados os excedentes necessários ao financiamento de um novo ciclo de P\&D.

A lei protege as criações intelectuais de natureza utilitária, industrial ou comercial, como os inventos, as marcas, os modelos de utilidade e os desenhos industriais. Contudo, garante que não haverá subordinação do interesse público ante o particular; no entanto, sob determinadas circunstâncias (de relevante interesse público), o próprio Estado poderá retirar a proteção outorgada, a exemplo de casos que, com maior frequência, são verificados na indústria farmacêutica e que levam ao que, comumente, se denomina de "quebra de patentes".

Apesar das contribuições, um sistema de proteção intelectual parece não ser suficiente para estimular as atividades de P\&D e, por conseguinte, o desenvolvimento científico e tecnológico de um país, o que tem levado os governos à edição de normas de fomento. Assim, ora estimulam a constituição de parcerias entre o ambiente produtivo e a academia, ora definem e regulamentam os mais diversos tipos de relacionamentos institucionais entre os atores que atuam nesse ambiente (pesquisadores, colaboradores, proprietários de ativos, financiadores etc.), estabelecendo deveres e assegurando direitos.

Por fim, a busca de novos arranjos institucionais tem se revelado um dos objetivos do governo brasileiro para a gestão da tecnologia no país, o que o torna um parceiro de grande potencial para as empresas que pretendem investir em P\&D, como será visto a seguir.

\section{Os fundos setoriais}

Em que pese o reconhecimento acerca de sua importância, os gastos com P\&D sempre tiveram que disputar a prioridade de alocação orçamentária com as demais demandas nacionais (saúde, educação, segurança etc.). Lembrando que, historicamente, no Brasil, o setor público sempre esteve à frente dos gastos com $\mathrm{P} \& \mathrm{D}$, é de se concluir que, de uma maneira ou de outra, os legisladores sempre contemplaram com alguns recursos essas atividades. Contudo, como 
resultado do Programa de Desestatização promovido pelos governos F. Collor de Melo e F. H. Cardoso, várias empresas estatais que até então se destacavam nas atividades de P\&D (nas áreas de telecomunicações, siderurgia, energia, entre outras) foram transferidas à iniciativa privada. Surgiu um problema: como assegurar a continuidade das pesquisas nessas áreas, evitando não só a perda e o atraso no nível de conhecimento acumulado, como também que o centro dessa inteligência fosse transferido, já que entre os novos acionistas alguns eram residentes no exterior? A resposta veio na forma da constituição de fundos setoriais.

Os fundos, ao contrário dos impostos, constituem fontes de recursos vinculados, portanto, com destinação específica, e têm origem quando há maioria, senão consenso, na Casa Legislativa competente para sua aprovação. Assim, os Fundos têm sido amplamente utilizados tanto pelo governo federal quanto pelas autoridades subnacionais quando pretendem excluir da disputa política os recursos destinados a determinados fins, havendo, por isso, inúmeros Fundos nas contas públicas brasileiras, alguns de caráter regional, outros setoriais. Criados por lei de iniciativa do Poder Executivo, só poderão ser modificados ou extintos através de outra lei, o que lhes confere maior estabilidade institucional e os sobrepõe aos mandatos dos governantes, razão pela qual também são alvos de críticas e sofrem oposição.

Assim, às leis de propriedade intelectual, a partir de 1999, somam-se os fundos setoriais (FS) como instrumentos governamentais de incentivo às atividades de P\&D. Entre os setores contemplados, inicialmente aqueles que passaram por processo de privatização e foram, por algum critério, considerados estratégicos: energia elétrica, telecomunicações e a de exploração de petróleo. Os FS contribuíram duplamente para o aumento no volume de recursos disponíveis: pelo maior aporte governamental (aos FS é assegurado um percentual fixo calculado sobre o faturamento das empresas do setor, em geral, concessionárias do governo) e pela exigência da contraparte contratante (empresas, universidades etc.). Destarte, além de ampliar o volume geral de recursos disponíveis, estimulando e fortalecendo o sistema de C\&T nacional, os FS tendem a assegurar a estabilidade de fluxo para o financiamento e o maior comprometimento dos contratantes não governamentais.

Através de editais, o governo federal oferta e coloca em disputa os recursos disponíveis para financiamento de projetos em áreas e setores considerados prioritários em razão do alinhamento com outras políticas, do efeito multiplicador, entre outros critérios. As dimensões continentais, ao lado das acentuadas desigualdades observadas no país, fazem com que os FS sejam, 
concomitantemente, instrumentos de redução de desigualdades regionais, devendo ser destinados $30 \%$ dos recursos às regiões menos favorecidas.

Se de início os FS tiveram como argumento de constituição o Programa de Desestatização, hoje eles já se encontram disseminados entre as mais diversas áreas, podendo-se mesmo dizer que a constituição de fundos, em si, é uma diretriz de política pública. Assim, até esta data já foram constituídos 16 fundos que destinam recursos para os seguintes setores: 1) Aeronáutico; 2) Agronegócios; 3) Amazônia; 4) Transporte Aquaviário e Construção Naval; 5) Biotecnologia; 6) Energia; 7) Espacial; 8) Recursos Hídricos; 9) Tecnologia da Informação; 10) Infraestrutura; 11) Minérios; 12) Petróleo e Gás Natural; 13) Saúde; 14) Transportes Terrestres; 15) o Fundo Verde Amarelo - que incentiva a interação empresa-universidade em projetos de inovação, empreendedorismo e cooperação tecnológica; e, 16) o de Telecomunicações (MCT, 2009).

Conforme se verifica, é bastante amplo o espectro de temas e campos de estudos e pesquisas passíveis de financiamento com recursos dos fundos, cobrindo desde os conhecimentos com foco regional, como é o caso do Amazônia, até as investigações em áreas de ponta, a exemplo da biotecnologia e espacial, não ficando à margem, todavia, pesquisas aplicadas nas áreas de transportes. Encontram-se, assim alinhadas, as políticas econômicas, de C\&T e os projetos sociais do governo.

Se o suprimento de recursos para o desenvolvimento científico e tecnológico apoiado na P\&D foi equacionado com a constituição dos FS, não menos importante é o processo de análise, avaliação e seleção das grandes áreas que serão beneficiárias desses recursos. Há que se tecer breves comentários sobre uma importante instituição também recentemente criada: o Centro de Gestão de Estudos Estratégicos (CGEE).

\section{o Centro de Gestão de Estudos Estratégicos (CGEE)}

Preliminarmente, cabe esclarecer que no Brasil, no topo da hierarquia do setor público federal se situam os Ministérios e, entre esses, cabe, principalmente, ao Ministério da Ciência e Tecnologia (MCT) a definição das políticas públicas afetas à $\mathrm{C} \& \mathrm{~T}$ e à $\mathrm{P} \& \mathrm{D}$, bem como dirigir e coordenar sua implementação. Inúmeras entidades, públicas, privadas e não governamentais concorrem para a efetividade das políticas públicas, contudo merece destaque o CGEE.

O Centro de Gestão de Estudos Estratégicos (CGEE), vinculado ao MCT, foi constituído como pessoa jurídica independente e na forma de associação civil sem fins lucrativos e tem como finalidade precípua a promoção do desen- 
volvimento científico e tecnológico no país. Conforme seu estatuto, o CGEE tem por objetivos: promover e realizar estudos e pesquisas prospectivas de alto nível na área de ciência e tecnologia e suas relações com setores produtivos; promover e realizar atividades de avaliação de estratégias e de impactos econômicos e sociais de políticas, programas e projetos científicos e tecnológicos.

O CGEE é, portanto, um amplo Fórum que reúne representantes do governo, do setor produtivo (empresários e trabalhadores) e do meio acadêmico-científico, do qual se espera, como produto do encontro dessas partes, senão um consenso, uma agenda de convergência quanto às prioridades de políticas públicas na área do desenvolvimento científico e tecnológico.

\section{A lei da inovação}

A Lei no 10.973/2004, que dispõe sobre incentivos à inovação e à pesquisa científica e tecnológica no ambiente produtivo e dá outras providências, conhecida como Lei da Inovação, é um dos mais recentes instrumentos de que dispõe o governo sobre incentivos à inovação e à pesquisa científica e tecnológica no ambiente produtivo. Em seu art. 1ํo pode ser lido: "Esta Lei estabelece medidas de incentivo à inovação e à pesquisa científica e tecnológica no ambiente produtivo, com vistas à capacitação e ao alcance da autonomia tecnológica e ao desenvolvimento industrial do País, nos termos dos arts. 218 e 219 da Constituição" (Brasil, 2009).

Ademais, é claro o propósito do governo em promover a aproximação da academia com o setor produtivo. Procura dirimir quaisquer questionamentos, até então existentes, acerca das relações profissionais e da atuação conjunta dos profissionais desses setores, bem como o compartilhamento de seus ativos e instalações para as atividades de pesquisa.

Agora, ao amparo da lei, os governos da União, dos estados, do Distrito Federal, e dos municípios, através dos respectivos aparelhos do Estado, podem estimular e apoiar a constituição de alianças estratégicas e o desenvolvimento de projetos de cooperação envolvendo empresas nacionais, Instituição Científica e Tecnológica (ICT - órgão ou entidade da administração pública que tenha por missão institucional, entre outras, executar atividades de pesquisa básica ou aplicada de caráter científico ou tecnológico) e organizações de direito privado sem fins lucrativos voltadas para atividades de P\&D, que objetivem a geração de produtos e processos inovadores. Da configuração de redes construídas ou mantidas com o apoio dessa lei poderão participar os projetos internacionais de pesquisa tecnológica, bem como as ações de empreendedo- 
rismo tecnológico e as de criação de ambientes de inovação, inclusive incubadoras e parques tecnológicos.

A participação minoritária da União e suas entidades no capital de empresa privada que tenha como intuito o desenvolvimento de projetos científicos ou tecnológicos para obtenção de produto ou de processo inovadores também está prevista na lei. O Estado poderá atuar como investidor-capitalista de risco em empreendimentos cuja análise demonstre ser aceitável o nível de risco, pois, em se tratando de recursos públicos, as aplicações devem ser de natureza predominantemente conservadora.

A lei define as linhas mestras do estímulo à inovação nas empresas nacionais mediante a "concessão de recursos financeiros, humanos, materiais ou de infraestrutura, a serem ajustados em convênios ou contratos específicos, destinados a apoiar atividades de P\&D”. Contudo, os estímulos não são livres, sua concessão é condicionada ao enquadramento nas prioridades da política industrial e tecnológica nacional.

Por ser recente, ainda não há evidências empíricas que autorizem análises e avaliações definitivas ou mesmo iniciativas para corrigir eventuais lacunas e desvios que a lei possibilita. Todavia, as conjecturas são alvissareiras, por atender uma demanda antiga da comunidade de pesquisadores acadêmicos que, informalmente, mantinham de maneira irregular relações profissionais e de parceria com o ambiente corporativo. Ao trazer as empresas privadas para dentro das ICT (a exemplo das universidades públicas) e ao possibilitar que os pesquisadores universitários (servidores públicos) atuem junto às empresas privadas, a legislação superou resistências e rompeu velhos paradigmas; a coparticipação, dos servidores-pesquisadores, nos ganhos provenientes dos resultados de pesquisas realizadas nas universidades públicas não é menos relevante.

Portanto, se, de um lado, a Lei de Inovação consagra antigos papéis dos governos (o de fomento, o de regular e o de regulamentar - Sábato), de outro, a partir da legalidade conferida às parcerias, ao compartilhamento e à complementação de recursos entre os vértices, inova e avança quando induz e desafia para o surgimento de novos arranjos institucionais.

Definidos os papéis de cada agente, bem como a estrutura básica do sistema nacional de inovação, sucedem iniciativas mais pontuais, a exemplo do Criatec - "Fundo de Investimento com a finalidade de capitalizar as micro e pequenas empresas inovadoras de capital semente [grifo desses autores] e de lhes prover um adequado apoio gerencial" (BNDES, 2009). Trata-se de um programa governamental que pretende contribuir para o equacionamento e a 
solução de dois grandes problemas que afetam os empreendedores inovadores: o do acesso ao capital de risco e a carência de expertise gerencial (Shanley, 1998; Gompers e Lerner, 2001).

De maneira análoga aos demais fundos, o Criatec também possui sua política de investimentos, dando preferência às micro e pequenas empresas inovadoras, que atuem nos setores de tecnologia da informação, biotecnologia, novos materiais, nanotecnologia, agronegócios, todas reconhecidas como tecnologias de ponta e com repercussão em todo o tecido produtivo nacional.

Por fim, cabe notar que, ao amparo da Lei de Inovação, até mesmo como acionista minoritário o Banco Nacional de Desenvolvimento Econômico e Social (BNDES) - maior entidade de fomento do governo brasileiro - poderá estimular as novas iniciativas; de outro lado, é possível que aos empreendedores descapitalizados seja ofertada a possibilidade de negociação, ex-ante facto, dos futuros direitos de propriedade e exploração comercial.

\section{As parcerias público-privada (PPP)}

Em complemento à Lei da Inovação, em 30 de dezembro de 2004, o Poder Executivo federal sancionou a lei que "institui normas gerais para licitação e contratação de parceria público-privada no âmbito da administração pública", a Lei no 11.079/2004, conhecida como a Lei das PPP. Ao contrário da Lei de Inovação, a Lei das PPP não tem como foco específico o desenvolvimento científico e tecnológico do país, mas cria a possibilidade de novos arranjos institucionais que podem vir a favorecer esse desenvolvimento. Recentes no Brasil, e no plano federal ainda em fase de planejamento, as PPP já têm uma experiência acumulada, sobretudo na Europa (Inglaterra, Irlanda, Portugal, Hungria, entre outros). Savas (2000:106), por exemplo, sobre as PPP informa que

[...] it refers to a formal collaboration between business and civic leaders and local government officials to improve the urban condition [...] corporations go beyond their usual role in the marketplace and become involved in schools, job training, downtown revitalization, urban redevelopment, and much more. Government becomes more than a tax collector and provider of conventional municipal services and becomes a real-estate developer, business lender, and so on.

No mundo, as PPP são constituídas através de um complexo conjunto de contratos que envolvem as entidades governamentais e as organizações 
privadas (concessionárias, agentes financeiros, consultorias, securitários etc.), entre outras, mediadas por uma sociedade de propósito específico (SPE). No que se refere ao tema ora em debate, as vantagens das PPP, assinaladas por vários autores (Grimsey e Lewis, 2004; Akintoye, Beck e Hardcastle, 2003), são a agilidade na condução das atividades (compra, venda, contratação, investimentos etc.) e a modernização que trazem à prestação do serviço público contratado. As SPE, portanto, tendem a ser as portas de entrada das inovações no setor público, sobremodo aquelas aplicadas nas áreas da saúde, saneamento, transporte, comunicações, entre outras. Ademais, nas garantias oferecidas nas concessões às PPP devem, também, exercer um efeito positivo atraindo novos (e inovadores) fornecedores, até então mantidos à distância devido à burocracia estatal.

Outros vínculos, contudo, aproximam as PPP do tema central deste artigo: o espaço de possibilidades que permite vislumbrar para novos e criativos arranjos institucionais para fins de realização das atividades de P\&D, sobretudo quando a Lei de PPP é combinada à Lei de Inovação. A saber:

v em tese, será possível que uma organização privada (isolada ou em forma de consórcio) construa, às suas expensas, uma unidade de pesquisa (um prédio para abrigar laboratórios e pesquisadores) cujos produtos ou serviços (vacinas, softwares etc.), quando colocados no mercado, proporcionarão, então, a amortização e o retorno do capital investido. Combinada com a Lei de Inovações, que autoriza a formação de parcerias com os pesquisadores das instituições governamentais de ensino, as possibilidades são, então, potencializadas;

v a criação de polos, parques e incubadoras tecnológicas se incluem na mesma diretriz; e sem pretender ser exaustivo,

v os contratos de P\&D compartilhada, com cláusula de risco, também são possibilidades a serem consideradas no novo ambiente.

No mundo, como evidencia a literatura teórica e empírica (Savas, 2000; Stainback, 2000), os contratos de PPP traduzem, basicamente, duas preocupações: primeiro, identificar os principais riscos do projeto (inerentes a quaisquer empreendimentos) e, segundo, distribuí-los entre os que reunirem as melhores competências para seu adequado gerenciamento; assim, conseguem aumentar o value for money dos recursos da sociedade, sejam eles privados ou públicos. 


\section{Plano de Ação 2007-2010 do Ministério da Ciência e Tecnologia (MCT)}

O governo brasileiro lançou, em 2007, o Plano de Aceleração de Crescimento (PAC), um conjunto de diretrizes, prioridades, regras, compromissos de ação e recursos, que propôs alcançar um crescimento econômico, mínimo, de $5 \%$ a.a., a partir de 2007. Para isso, incentivará o investimento privado, aumentará o investimento público em infraestrutura e removerá os entraves burocráticos ao crescimento, bem como pretende uma maior integração entre o governo e o setor privado. As medidas do PAC se organizam da seguinte maneira: investimento em infraestrutura, estímulo ao crédito e financiamento, melhora do ambiente de investimento, desoneração e aperfeiçoamento do Sistema Tributário e medidas fiscais a longo prazo (MF, 2009).

Em harmonia com o PAC, o MCT define um Plano de Ação 2007-2010, tendo como base a Ciência, Tecnologia e Inovação para o desenvolvimento nacional. Consiste em um conjunto de ações, iniciativas e programas voltados ao papel da C,T\&I no desenvolvimento sustentável do país. Estes abragem tanto o setor público quanto o privado, buscam fomentar as atividades P,D\&I nas empresas e impulsionar a pesquisa cientifica e tecnológica em todas as áreas de conhecimento. Trabalha em quatro frentes: 1) a expansão e consolidação do Sistema Nacional de C,T\&I; 2) a promoção da inovação tecnológica nas empresas; 3) o estímulo à P,D\&I em áreas estratégias; e 4) a contribuição da C,T\&I para o desenvolvimento social (MCT, 2009).

Todos os eixos estratégicos do Plano de Ação contribuem diretamente para o desenvolvimento científico-tecnológico do país; entretanto, tendo como norte a parceria entre empresa e governo, o fomento à inovação tecnológica nas empresas se destaca entre as outras frentes propostas no plano. Essa, pois, foi desenvolvida em três partes, primeiramente no que se refere ao apoio à inovação tecnológica nas empresas. Este advém do suporte financeiro às atividades de $\mathrm{P}, \mathrm{D} \& \mathrm{I}$, da inserção de pesquisadores nas empresas e da capacitação de recursos humanos no setor privado para a Inovação, da aproximação entre empresas e ICTs. Além da implementação de centros de P,D\&I empresariais, desvinculando a responsabilidade, apenas dos centros de pesquisa, da produção de pesquisas e inovação tecnológica.

Nesta ação do governo, a segunda parte é o fortalecimento da tecnologia para inovação nas empresas, que será desenvolvida pelo Sistema Brasileiro de Tecnologia (Sibratec). Este é formado por institutos de pesquisas tecnológicas e centros universitários de iniciativas pública e privada, com base em temas que dão suporte ao desenvolvimento de empresas industriais e de serviços. 
A prestação de serviços de pesquisa e tecnológicos, fornecendo transferência e assistência de tecnologia para o setor empresarial, é outra manobra para a criação de tecnologia para inovação.

$\mathrm{O}$ incentivo à criação e à consolidação de Empresas Intensivas em Tecnologia é a parte do Plano de Ação que será posto em prática por meio do Programa Nacional de Apoio às Incubadoras e Parques Tecnológicos (PNI), do Programa Inovar. Fomentará a criação e a ampliação da indústria de Venture Capital e pelo poder de compra do Estado, que assegurará mercado para as empresas brasileiras, principalmente as de alta tecnologia, estimulando o desenvolvimento tecnológico das empresas nacionais de tecnologia.

Conforme verificado, o Plano de Ação do MCT anuncia várias frentes de ação em busca do desenvolvimento tecnológico-científico do país, ratificando que este tipo de iniciativa dos governos é essencial, sobretudo para os países em desenvolvimento que, assim, podem fortificar as suas economias e se tornarem mais competitivos.

Ao conjunto de iniciativas relacionadas neste estudo: as Leis de Proteção à atividade intelectual, a Lei de Inovação, o CGEE, a Lei das PPP e o Plano de Ação do MCT, outras poderiam ser adicionadas, a exemplo: a legislação que autoriza que o valor aplicado em P\&D seja deduzido do imposto de renda, assim como a redução das taxas aplicadas à importação de materiais destinados à pesquisa. Tais fatos parecem não deixar dúvidas quanto à preocupação e ao comprometimento do governo para com a P,D\&I, o que o torna um efetivo parceiro, embora nem sempre lembrado, para as empresas que pretendam fazer da P\&D uma alavanca para a inovação. Estas ações também demonstram como o Brasil, sendo um país em desenvolvimento, está agindo em busca de uma maneira adequada para gerenciar tecnologias.

\section{Considerações finais}

O objetivo deste trabalho foi de apresentar e discutir as principais iniciativas promovidas pelo governo brasileiro, nos últimos 10 anos, que têm como propósito geral inverter a conhecida fragilidade do país no campo do desenvolvimento científico e tecnológico e redesenhar o mapa das atividades de P\&D no país, bem como a participação relativa do setor público e privado. Promovendo também uma maior integração entre os dois, aproximando as instituições de ensino e pesquisa dedicadas à pesquisa básica, ao setor produtivo, que se concentra na pesquisa aplicada, direcionada às suas plataformas de produção, que por muito tempo não teve diálogo com aquelas, 
afastando-se, assim, dos investimentos promotores de rupturas tecnológicas. O papel do governo neste quadro também se altera e passa a ser uma fonte de parceria para as empresas privadas.

Conforme se demonstrou, desde os anos 1990, através de sucessivas iniciativas, o governo brasileiro vem estruturando um sistema que não só confere proteção intelectual ao resultado proveniente dos esforços em P\&D como também atua estimulando o empreendedorismo, tanto no plano dos indivíduos quanto no das instituições. Sobre os fundos setoriais, pode-se dizer que é uma iniciativa clara de fomento a determinadas áreas estratégicas para o crescimento do país. Ao passo que a criação do CGEE trouxe à mesa de discussões agentes que até então se viam distantes do processo de escolha das políticas públicas no campo do desenvolvimento científico e tecnológico do país, mas que percebem hoje a necessidade da congruência de esforços para o crescimento do país e o aumento de divisas. As leis de Inovação e das PPP alavancaram as parcerias entre o governo, a iniciativa privada e os institutos de pesquisa e universidades, mas são importantes especialmente por criar as condições legais necessárias e indispensáveis ao surgimento de novos e criativos arranjos institucionais.

O papel e a proatividade do governo ainda são centrais, contudo tendentes a deixar de sê-lo. Pouco a pouco, na proporção direta em que as iniciativas governamentais ecoarem junto aos demais vértices, é de se esperar uma nova composição no perfil do processo de geração-desenvolvimento-difusão do conhecimento. No Brasil, o governo como agente fundamental na estruturação do arranjo institucional de investimentos em P\&D tem cumprido suas atribuições, por meio da incorporação da cultura de P,D\&I no setor privado, dos incentivos às parcerias entre empresas e institutos de pesquisa, investimento em recursos humanos para desenvolver as habilidades e conhecimentos necessários para que o país tenha uma indústria inovadora. Além das políticas públicas para sustentar todo esse quadro de fomento ao P,D\&I no país.

Desta forma, para as empresas o governo passa a ser parceiro em potencial para as atividades de P\&D. No entanto, do ponto de vista das empresas, ainda existem alguns limitadores para esta parceria, podendo ser citados: o tempo e os recursos direcionados para a formulação de projetos devido à burocracia, à dificuldade de estruturar as prestações de contas, em razão do grande número de comprovantes requisitados, e à imprevisibilidade das mudanças de regras, pois a natureza de recursos destinados à inovação pelo governo vai depender de escolhas políticas, ficando a empresa à mercê da situação política do país. Apesar desses fatores que desestimulam a parceria entre governo e empresa, no Brasil, os programas, incentivos, regulamentações e políticas pú- 
blicas se mostram constantes, proporcionando um ambiente estável, aumentando assim a confiança das empresas no governo como parceiro.

Como toda política pública, a análise e a avaliação quanto à sua efetividade demandarão ainda algum tempo. Contudo, as condições de entorno já foram estabelecidas pelo governo federal, e algumas medidas, tratando-se de legislação geral, ainda comportam e dependem de especificação dos governos subnacionais e locais.

Caso o setor privado e as instituições de pesquisa e universidades respondam à expectativa do governo, é de se esperar que a médio e longo prazo, em torno de 10 anos, ocorra uma mudança significativa no cenário técnicocientífico brasileiro. Evitar a evasão de cérebros, aumentar os investimentos e o nível de emprego em setores intensivos em tecnologia, que em geral proporcionam elevado valor agregado, bem como são poupadores de energia não renovável, são, entre outros, objetivos que podem ser alinhados. Essas mudanças, ao final, irão se refletir na matriz insumo-produto do país, isto é, em uma nova composição setorial e regional do PIB brasileiro e uma formação de excedentes mais positiva.

\section{Referências}

AKINTOYE, A.; BECK, M.; HARDCASTLE, C. (Ed.). Public-private partnerships: managing risks and opportunities. UK: Blackwell Science, 2003.

ALLEN, T.J. et al. Government influence on the process of innovation in Europe and Japan. Research Police, v. 7, n. 1, p. 101-116, jan. 1978.

BNDES. Disponível em: <www.bndes.gov.br/programas/outros/criatec.asp>. Acesso em: 30 maio 2009.

BRASIL. Constituição Federal. Disponível em: <www.senado.gov.br> . Acesso em: 30 maio 2009.

ETZKOWITZ, Henry. Innovation in innovation: the triple helix of university-industrygovernment relations. Social Science Information, v. 42, n. 3, p. 293-337, 2003.

FREEMAN, Chris. Innovations systems: city-state, national, continental and subnational. Rio de Janeiro: IE/UFRJ. 1998. (Nota Técnica)

GERSHENKRON, A. Economic backwardness in historical perspective. Cambridge: Harvard University Press, 1962.

GOMPERS, P.A.; LERNER, J. The money of invention: how venture capital creates new wealth. Boston, USA: HBS Press, 2001. 
GRIMSEY, Darrin; LEWIS, Mervyn K. Public private partnerships: the worldwide revolution in infrastructure provision and project finance. USA, Northampton: Edward Elgar, 2004.

MARCOVITCH, J. et al. Inovação tecnológica e incentivos fiscais. Revista da Administração, São Paulo, v. 26, n. 1, p. 43-60, jan./mar. 1991.

MCT. Ministério da Ciência e Tecnologia. Disponível em: <www.mct.gov.br>. Acesso em: 22 maio 2009.

MF. Ministério da Fazenda. Disponível em: <www.fazenda.gov.br/portugues/releases/2007/r220107-PAC-integra.pdf>. Acesso em: 5 jun. 2009.

PAVITT, K.; WALKER, W. Government policies towards industrial innovation: a review. Research Policy, v. 5, n. 1, p. 11-95, jan. 1976.

SÁBATO, Jorge. Bases para un régimen de tecnología. In: STANZICK, Karl-Heinz; SCHENKEL, Peter (Ed.). Ensayos sobre política tecnológica en América Latina. Ecuador, Quito: Instituto Latinoamericano de Investigaciones Sociales, 1974.

SAVAS, E.S. Privatization and public-private partnerships. USA, NY: Seven Bridges Press, LLC, 2000.

SCHUMPETER, J.A. Teoria do desenvolvimento econômico: uma investigação sobre lucros, capital, juro e ciclo econômico. 3. ed. São Paulo: Nova Cultural, 1988. (Os Economistas)

SHANLEY, Richard P. Financing technology's frontier: decision-making models for investors and advisors. USA, Canada: John Wiley \& Sons Inc, 1998.

STAINBACK, John. Public/private finance and development. USA, NY: John Wiley \& Sons, 2000. 